\title{
Serum lactate dehydrogenase as an early marker for outcome in patients treated with anti-PD-1 therapy in metastatic melanoma
}

\author{
S Diem ${ }^{1,4}$, B Kasenda ${ }^{1,4}$, L Spain ${ }^{1}$, J Martin-Liberal ${ }^{1,2}$, R Marconcini ${ }^{3}$, M Gore ${ }^{1}$ and J Larkin *,1 \\ ${ }^{1}$ Department of Medical Oncology, Royal Marsden Hospital NHS Foundation Trust, Fulham Road, London SW36JJ, UK; \\ ${ }^{2}$ Department of Medical Oncology, Vall d'Hebron University Hospital, Vall d'Hebron Institute of Oncology (VHIO), Pg Vall \\ d'Hebron, 119-129, 08035 Barcelona, Spain and 'Department of Medical Oncology, Santa Chiara Hospital, via Roma 67, \\ 56100 Pisa, Italy
}

Background: Treatment with programmed death receptor-1 (PD-1) antibodies is associated with high response rates in patients with advanced melanoma. Reliable markers for early response and outcome are still sparse.

Methods: We evaluated 66 consecutive patients with advanced/metastatic melanoma treated with nivolumab or pembrolizumab between 2013 and 2014. The main objectives of this study were to investigate whether, first, serum lactate dehydrogenase (LDH) at baseline (normal vs above the upper limit of normal) correlates with overall survival (OS), and, second, whether the change of LDH during treatment predicts response before the first scan and OS in patients with an elevated baseline LDH.

Results: After a median follow-up of 9 months, patients with an elevated baseline LDH $(N=34)$ had a significantly shorter OS compared with patients with normal LDH ( $N=32$; 6-month OS: $60.8 \%$ vs $81.6 \%$ and 12 -month OS: $44.2 \%$ vs $71.5 \%$ (log-rank $P=0.0292)$. In those 34 patients with elevated baseline $L D H$, the relative change during treatment was significantly associated with an objective response on the first scan: the 11 (32\%) patients with partial remission had a mean reduction of $-27.3 \%$ from elevated baseline $\mathrm{LDH}$. In contrast, patients with progressive disease $(N=15)$ had a mean increase of $+39 \%$. Patients with a relative increase over $10 \%$ from elevated baseline LDH had a significantly shorter OS compared with patients with $\leqslant 10 \%$ change (4.3 vs 15.7 months, log-rank $P<0.00623$ ).

Conclusions: LDH could be a useful marker at baseline and during treatment to predict early response or progression in patients with advanced melanoma who receive anti-PD-1 therapy.

The prognosis of metastatic melanoma has improved during the last few years. Until recently, treatment with dacarbazine and interleukin-2 (IL-2) yielded poor responses coupled with significant toxicity; however, some patients achieved durable responses with high-dose IL-2 (Chapman et al, 1999; Atkins et al, 2000). In tumours with a BRAF mutation, mitogen-activated protein kinase (MAPK) pathway inhibitors have demonstrated high response rates and a survival advantage compared with chemotherapy. Nevertheless, median duration of response is 6-11 months and almost all patients eventually develop resistance to these drugs (Chapman et al, 2011; Flaherty et al, 2012; Hauschild et al, 2012; Larkin et al, 2014; Long et al, 2014, 2015; Robert et al, 2014a).

The first novel approved immunomodulatory drug was the cytotoxic T-lymphocyte antigen- 4 antibody ipilimumab. Although response rates are low (10-15\%), 20\% of all patients have durable benefit (Hodi et al, 2010; Larkin et al, 2015; Robert et al, 2015; Schadendorf et al, 2015). Ipilimumab is now a standard first-line treatment in metastatic melanoma. Anti-programmed death

*Correspondence: Dr J Larkin; E-mail: james.larkin@rmh.nhs.uk

${ }^{4}$ These authors contributed equally to this work.

Received 12 August 2015; revised 12 November 2015; accepted 7 December 2015; published online 21 January 2016

(c) 2016 Cancer Research UK. All rights reserved 0007 - 0920/16 
receptor-1 (anti-PD-1) antibodies, another class of immunomodulatory drugs, induce tumour cell death by blocking the inhibitory interaction between PD-1 on $\mathrm{T}$ cells and its ligand PD-L1 on cancer cells (Robert et al, 2014c). Currently available PD-1 antibodies are nivolumab and pembrolizumab, which both improve response rates, progression-free and overall survival (OS) compared with chemotherapy and ipilimumab in both ipilimumab-treated and -naive patients (Robert et al, 2014b, c, 2015; Larkin et al, 2015; Ribas et al, 2015; Weber et al, 2015). The combination of ipilimumab and nivolumab demonstrated an overall response rate of $57 \%$ with a prolonged progression-free survival compared with single-agent therapy, but grades 3 and 4 toxicity is increased (55\%; Larkin et al, 2015).

Baseline serum lactate dehydrogenase (LDH) is an established, independent prognostic factor for survival (Eton et al, 1998; Manola et al, 2000; Agarwala et al, 2009; Weide et al, 2012; Delyon et al, 2013; Kelderman et al, 2014) and a part of the American Joint Committee on Cancer classification for stage IV melanoma (Balch et al, 2009). In recent trials with either ipilimumab or an anti-PD-1 agent, patients with elevated baseline $\mathrm{LDH}$ were included, but no subgroup analyses regarding efficacy were reported (Larkin et al, 2015; Robert et al, 2015; Weber et al, 2015). Only KEYNOTE-002 reports a subgroup analysis that did not show a difference between patients with normal and elevated LDH (Ribas et al, 2015). The PD-L1 status on tumours may predict benefit from anti-PD-1 treatment, but no definitive conclusions can be drawn yet (Larkin et al, 2015; Robert et al, 2015; Weber et al, 2015).

In daily practice, reliable clinical markers for response and outcome in the era of anti-PD-1 immunotherapy are lacking. In this study, we investigated whether (i) $\mathrm{LDH}$ at baseline in anti-PD-1-treated patients is of prognostic relevance, and (ii) whether a relative change in $\mathrm{LDH}$ could serve as an early marker for outcome.

\section{PATIENTS AND METHODS}

We retrospectively analysed all patients with advanced/metastatic melanoma at the Royal Marsden Hospital NHS Foundation Trust (United Kingdom) treated with PD-1 antibodies, either pembrolizumab or nivolumab. Patients were treated between 2013 and 2014, and had at least one infusion of pembrolizumab or nivolumab. Anonymised patient data, clinical features and laboratory values were extracted from electronic patient records. The local Research Ethics Board approved this study.

Treatment and response assessment. Patients received either pembrolizumab ( $2 \mathrm{mg} \mathrm{kg}^{-1}$ every 3 weeks and $10 \mathrm{mg} \mathrm{kg}^{-1}$ every 2 or 3 weeks) or nivolumab $\left(3 \mathrm{mg} \mathrm{kg}^{-1}\right.$ every 2 weeks) as monotherapy. Response was evaluated by computed tomography (CT). The categories of response were complete remission, partial remission (PR), stable disease (SD) or progressive disease (PD) as per RECIST criteria (version 1.1; Eisenhauer et al, 2009). Serum $\mathrm{LDH}$ was measured at least within 3 days before administration of anti-PD-1 antibodies.

Statistical analysis. We stratified patients according to baseline $\mathrm{LDH}$ values (below or equal to the upper limit of normal (ULN) compared above ULN). We explored response and OS-1 (time from starting anti-PD-1 therapy until death due to any cause) stratified by baseline $\mathrm{LDH}$ in all patients. This analysis was intended to investigate whether baseline $\mathrm{LDH}$ is of prognostic value in patients treated with anti-PD-1 antibodies. We did one sensitivity analysis using Cox regression in which we adjusted for the line of treatment in which the anti-PD-1 antibody was applied (first $v s$ second line and higher).
The main objective of our study was to investigate whether changes in serum LDH before the first radiological assessment could predict response and OS-2 (time between the last $\mathrm{LDH}$ measurement before the first radiological assessment until death to any cause). For this, we only considered patients with an LDH above ULN at the time of starting anti-PD-1 treatment (baseline value), had at least one post-baseline $\mathrm{LDH}$ value and had at least one CT scan. All other patients were excluded from this analysis. Based on these included patients, we calculated the relative increase or decrease from the baseline $\mathrm{LDH}$ value of consecutive serum $\mathrm{LDH}$ values before the first CT. If the value at cycle 2 was not available, we used the value from cycle 3 and vice versa for analysis. If both values were available, we used the mean for analysis. The difference in the relative change of LDH from baseline by response status was illustrated using box plots. We have also arbitrarily chosen a cutoff of at least $+10 \%$ from baseline and categorised patients accordingly. We did not choose a smaller value because this may have been at risk to intra-patient variability. We also investigated whether the relative change of $\mathrm{LDH}$ from baseline (as continuous variable) predicts response (PD vs no-PD) using logistic regression adjusted for line of treatment (first $v s$ second line and higher) in a sensitivity analysis. To account for possible guarantee-time bias in the analysis of OS-2, we only included patients still alive and without progression at the second cycle. We hypothesised that an early increase of LDH would allow prediction of progression and shorter OS-2. We took the above-mentioned cutoff of $10 \%$ to explore this. We used the Kaplan-Meier method to investigate OS-1 and OS-2. Patient follow-up time was estimated by using the inverse Kaplan-Meier method. Analysis of variance (ANOVA) was used to compare means among groups. A $P$-value $<0.05$ was considered significant; reported $P$-values are exploratory in nature. Statistical analyses were performed with $\mathrm{R}$ version 3.1.2 (www.rproject.org).

\section{RESULTS}

Patient characteristics. We included 66 patients with advanced melanoma. Baseline characteristics are summarised in Table 1. Most patients were treated with pembrolizumab (46 out of 66, $70 \%$ ) and the majority of the patients had stage M1c disease (57 out of $66,86 \%)$. Around half of the patients were treated with an anti-PD-1 agent in the third line after progression on chemotherapy or ipilimumab. Thirty-four out of 66 patients (52\%) had an elevated LDH at baseline. The median follow-up from start of antiPD-1 treatment for all patients was 9 months (95\% CI, 6.7-15.4 months).

LDH at baseline. Thirty-four out of 66 patients $(51.5 \%)$ had an elevated serum LDH at baseline. Of those 34 patients, $5(14.7 \%)$ and $13(38.2 \%)$ had a value $f 1.5 \times$ ULN and $2.0 \times \mathrm{ULN}$, respectively. The response rates observed on the first CT scan stratified by LDH level at baseline are summarised in Table 2 . The OS-1 for all patients at 6 and 12 months was 70.6\% (95\% CI, $59.8-$ 83.8 ) and $56.8 \%$ (95\% CI, 43.8-73.6), respectively. The OS-1 was significantly shorter in patients with elevated baseline LDH (median: 9.7 vs not reached; 6-month OS: 60.8\% (95\% CI, 45.481.4) vs 81.6 (95\% CI, 67.9-97.9); and 12-month OS: 44.2\% (95\% CI, 27.8-70.3) vs 71.5\% (95\% CI, 55.2-92.7); log-rank $P=0.0292$ ) (Figure 1). The sensitivity analysis adjusted for the line of treatment did not change our conclusions (data not shown).

LDH changes and response on first scan. For this analysis, only the 34 patients with elevated baseline $\mathrm{LDH}$ were considered. Of these, 29 patients $(85.3 \%)$ had at least one LDH measurement after baseline, and all 29 patients had at least one CT scan. 
Table 1. Patient characteristics

\begin{tabular}{|c|c|c|c|}
\hline & $\begin{array}{l}\text { LDH normal } \\
\quad(N=32)\end{array}$ & $\begin{array}{l}\text { LDH elevated } \\
\quad(N=34)\end{array}$ & Total \\
\hline \multicolumn{4}{|l|}{ Treatment } \\
\hline Nivolumab & $10(31.3)$ & $10(29.4)$ & $20(33.3)$ \\
\hline Pembrolizumab & $22(68.7)$ & $24(70.6)$ & $46(69.7)$ \\
\hline \multicolumn{4}{|l|}{ Sex } \\
\hline Female & $10(31.2)$ & $15(44.1)$ & 25 (37.9) \\
\hline Male & $22(68.8)$ & $19(55.9)$ & $41(62.1)$ \\
\hline \multicolumn{4}{|c|}{ ECOG Performance Status } \\
\hline 0 & $15(46.9)$ & $12(35.3)$ & $27(40.9)$ \\
\hline 1 & $17(53.1)$ & $22(64.7)$ & $39(59.1)$ \\
\hline \multicolumn{4}{|l|}{ Age (in years) } \\
\hline Median (IQR) & $55.3(49,64.8)$ & $60.1(50.2,67.4)$ & $56.2(49.1,66.8)$ \\
\hline \multicolumn{4}{|c|}{ BRAF mutation } \\
\hline No & $18(56.2)$ & $27(79.4)$ & $45(68.2)$ \\
\hline Yes & $13(40.6)$ & 7 (20.6) & $20(30.3)$ \\
\hline Unknown & $1(3.1)$ & $0(0)$ & $1(1.5)$ \\
\hline \multicolumn{4}{|c|}{ Number of organs involved before treatment } \\
\hline One & $5(15.6)$ & $1(2.9)$ & $6(9.1)$ \\
\hline Two & $12(37.5)$ & $12(35.3)$ & $24(36.4)$ \\
\hline Three & 9 (28.1) & 11 (32.4) & $20(30.3)$ \\
\hline Four & $2(6.2)$ & $3(8.8)$ & $5(7.6)$ \\
\hline Five & $1(3.1)$ & $4(11.8)$ & $5(7.6)$ \\
\hline Six & $2(6.2)$ & $3(8.8)$ & $5(7.6)$ \\
\hline Seven & $1(3.1)$ & $0(0)$ & $1(1.5)$ \\
\hline \multicolumn{4}{|l|}{ M stage } \\
\hline M1a & $5(15.6)$ & $1(2.9)$ & $6(9.1)$ \\
\hline M1b & 1 (3.1) & $2(5.9)$ & $3(4.5)$ \\
\hline M1c & $26(81.2)$ & $31(91.2)$ & $57(86.4)$ \\
\hline \multicolumn{4}{|c|}{ CNS metastases } \\
\hline Yes & $1(3.1)$ & $2(5.9)$ & $3(4.5)$ \\
\hline No & $31(96.9)$ & $32(94.1)$ & $63(95.5)$ \\
\hline \multicolumn{4}{|c|}{ Immunotherapy applied in which line } \\
\hline First & $5(15.6)$ & $6(17.6)$ & $11(16.7)$ \\
\hline Second & $10(31.2)$ & 7 (20.6) & $17(25.8)$ \\
\hline Third & $10(31.2)$ & $21(61.8)$ & $31(47)$ \\
\hline Fourth & $7(21.9)$ & $0(0)$ & $7(10.6)$ \\
\hline \multicolumn{4}{|l|}{ Baseline LDH } \\
\hline Median (IQR) & $150(130.2,164.2)$ & $304(218,487.5)$ & $197(151,309.5)$ \\
\hline \multicolumn{4}{|c|}{ Number of cycles applied } \\
\hline Median (IQR) & $5(4,17)$ & $4.5(2.2,9)$ & $5(3,12.8)$ \\
\hline
\end{tabular}

\section{Table 2. Response at first CT scan}

\begin{tabular}{|l|c|c|c|}
\hline Response & LDH normal & LDH elevated & Total \\
\hline PR & 32 & 34 & 66 \\
\hline PD & $11(34.4)$ & $11(32.4)$ & $22(33.3)$ \\
\hline SD & $13(40.6)$ & $20(58.8)$ & $33(50)$ \\
\hline Unknown & $7(21.9)$ & $3(8.8)$ & $10(15.2)$ \\
\hline $\begin{array}{l}\text { Abbreviations: CT = computed tomography; LDH = lactate dehydrogenase; PD = progressive } \\
\text { disease; PR= partial remission; SD = stable disease. }\end{array}$
\end{tabular}

Therefore, we included these 29 patients for the analysis regarding tumour response. The association between the changes in $\mathrm{LDH}$ before first response assessment is shown in Figure 2. Those 11 patients who achieved a PR had a marked relative reduction compared with their baseline value (mean change $-27.3 \%$; s.d. \pm 26.4 , range -69.9 to $2.1 \%$ ). Almost all patients showing PD $(N=15)$ had an increase compared with their baseline value (mean

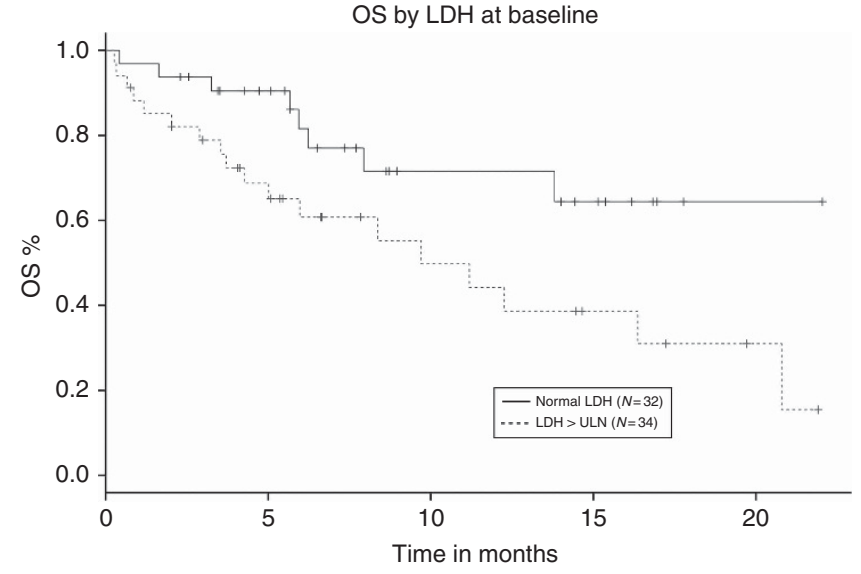

Figure 1. Overall survival in the entire cohort according to baseline LDH. Abbreviations: LDH, lactate dehydrogenase.

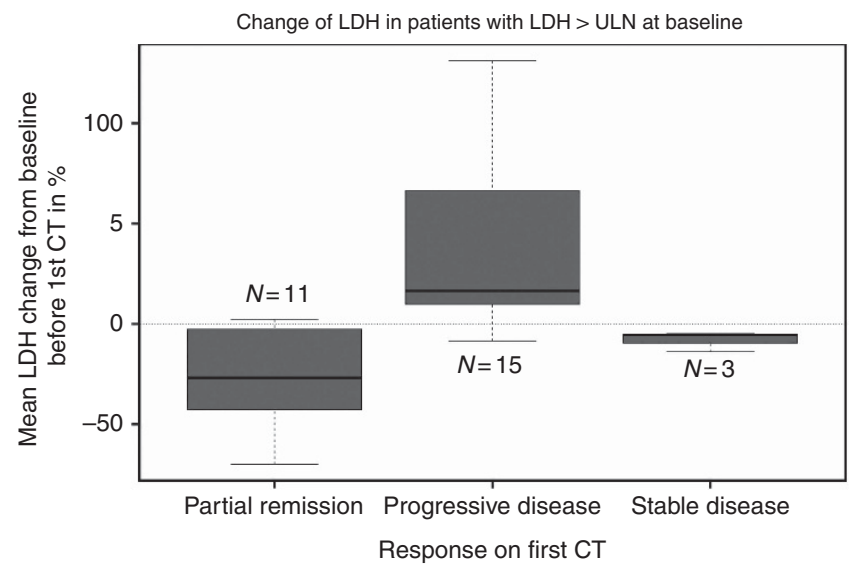

Figure 2. Association between changes in LDH before first CT scan and tumour response. Abbreviations: $\mathrm{CT}$, computed tomography; $\mathrm{LDH}$, lactate dehydrogenase.

change $+38.9 \%$, s.d. \pm 44.1 , range -8.5 to $131.1 \%$ ), whereas those three patients with SD had a mean change of $-8.0 \%$ (s.d. \pm 5.1 , range -13.9 to $-4.8 \%$ ). These differences in mean $\mathrm{LDH}$ change according to response were statistically significant by ANOVA $(P<0.001)$. The sensitivity analysis adjusted for the line of treatment did not change our conclusions (data not shown).

Eleven out of 29 patients (37.9\%) had a relative increase of $>10 \%$ compared with baseline and the remaining 18 (62.1\%) patients had a relative change of $\leqslant 10 \%$. All 11 patients with a relative increase of $>10 \%$ had documented PD on their first scan. Of those 18 patients with $\leqslant 10 \%$ increase, only 4 (22.2\%) patients developed PD on first scan, $11(61.1 \%)$ had a PR and $3(16.7 \%)$ had a SD.

LDH change and OS-2. Twenty-nine patients were included in the analysis of OS-2 to account for possible guarantee-time bias. Patients with a relative increase of $>10 \%(N=11)$ had a significant shorter median OS-2 compared with patients with $\leqslant 10 \%$ change from baseline $(N=18 ; 4.3 v s 15.7$ months, log-rank $P<0.00623$; Figure 3).

\section{DISCUSSION}

Our study shows that an increasing LDH during the first weeks of treatment with anti-PD-1 antibodies can predict disease 


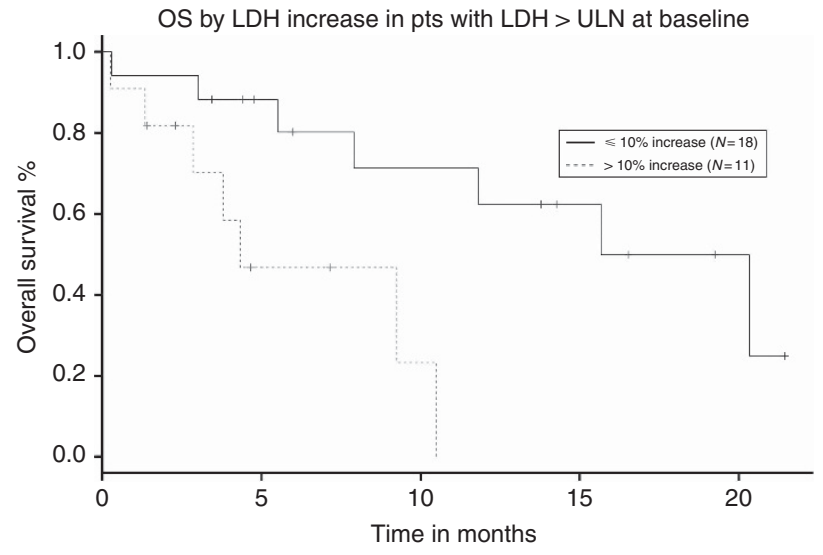

Figure 3. OS-2 calculated on LDH measurement before first radiological assessment until death to any cause depending on change in LDH. Abbreviations: LDH, lactate dehydrogenase; OS, overall survival.

progression before the first scan and is also associated with decreased survival. We also show that elevated LDH at baseline is associated with a significant, shortened survival.

Ipilimumab was the first approved immunotherapy and remains a standard first-line treatment option in many countries for advanced melanoma (Hodi et al, 2010; Robert et al, 2011). Nevertheless, the landscape of treatment for metastatic melanoma is changing rapidly. Promising response rates and OS rates have been achieved with nivolumab (Robert et al, 2014b; Larkin et al, 2015; Weber et al, 2015) and pembrolizumab (Robert et al, 2014c, 2015; Ribas et al, 2015). Also pembrolizumab has shown superiority compared with ipilimumab in a phase III trial of patients naive to immunotherapy (Robert et al, 2015). Both drugs, nivolumab and pembrolizumab, are already licenced in the United States of America and Japan, and will become standard treatment options for metastatic melanoma in Europe as well.

Smaller studies have shown that the combination of ipilimumab and nivolumab has superior clinical activity compared with ipilimumab alone, but toxicity was significantly increased (Wolchok et al, 2013; Postow et al, 2015). Recently, this data were confirmed in a large phase III trial. Nivolumab combined with ipilimumab and nivolumab alone resulted in significantly longer progression-free survival than ipilimumab alone in previously untreated patients with advanced melanoma. Grades 3 and 4 toxicity in the combination group was 55\% (Larkin et al, 2015).

It is likely that combination immunotherapy will become standard of care in fit and otherwise healthy patients with newly diagnosed advanced or metastatic melanoma. Nevertheless, higher efficacy will be at the cost of increased toxicity. To date, there is less experience in treating patients with the combination outside of a clinical trial in 'a real world setting'. In fragile patients, where the physician feels uncomfortable using the combination ipilimumab and nivolumab, we assume that many patients will therefore receive an anti-PD-1 agent as monotherapy upfront once available.

Serum $\mathrm{LDH}$ is a standardised and simple marker, which is easy to use in the clinic. High LDH is a well-known marker for poor outcome in the era of chemotherapy (Eton et al, 1998; Manola et al, 2000; Agarwala et al, 2009; Balch et al, 2009). We have recently shown that in patients treated with ipilimumab, an increasing baseline LDH_as part of a prognostic score with ECOG performance status and number of involved organs-was independently associated with poor survival (Diem et al, 2015). Two other studies confirmed this inverse correlation (Delyon et al, 2013; Kelderman et al, 2014). Only one trial with an anti-PD-1 agent evaluated the predictive value of $\mathrm{LDH}$; however, there was no difference regarding efficacy between patients with normal LDH or elevated LDH (Ribas et al, 2015).

About half of all patients in our real world cohort had an elevated $\mathrm{LDH}$ at baseline. We are not aware of any study that investigates the role of monitoring $\mathrm{LDH}$ during treatment in patients who receive anti-PD-1 treatment. We have shown that $\mathrm{LDH}$ could provide helpful information to guide decision-making during treatment even before the first scan. For example, in patients who already have an increased LDH at baseline, further increase during the first 2 weeks likely reflects progression of disease under treatment with anti-PD-1 monotherapy. In this case, combination immunotherapy or a change to MAPK-targeted agents could be considered. In an era of increasing choice and expensive treatment, determination of biomarkers is paramount. However, we cannot say whether an early switch to, for example, combination immunotherapy would improve prognosis. A randomised setting would be needed to answer this question. An optimal sequencing of immunotherapy with MAPK inhibitors also needs to be determined prospectively.

We are aware of limitations of our study. Owing to the retrospective design, there may be a risk of patient selection bias; however, we included all consecutive patients at our centre. Another limitation is the relatively small number of patients, and we had to reduce the number even further in our landmark analysis to maintain methodological rigour. A third point is the lack of information about the PD-L1 status in the tumour, which may be a potential predictor for efficacy (Robert et al, 2014b; Larkin et al, 2015; Weber et al, 2015). We cannot exclude that PD-L1-positive tumours may be over-represented in the group with low LDH who have a favourable diagnosis in our population.

We conclude that $\mathrm{LDH}$ could be a very useful marker at baseline and during treatment in patients treated with PD-1 antibodies for advanced melanoma. In daily practice, this would be helpful for counselling patients before initiating therapy and guiding treatment decisions during the course of treatment. Further prospective evaluation is required to confirm our results.

\section{ACKNOWLEDGEMENTS}

Stefan Diem was supported by the Swiss Cancer League. Professor Martin Gore and Dr James Larkin are supported by the Royal Marsden Hospital/ICR Biomedical Research Centre for Cancer.

\section{CONFLICT OF INTEREST}

The authors declare no conflict of interest.

\section{REFERENCES}

Agarwala SS, Keilholz U, Gilles E, Bedikian AY, Wu J, Kay R, Stein CA, Itri LM, Suciu S, Eggermont AMM (2009) LDH correlation with survival in advanced melanoma from two large, randomised trials (Oblimersen GM301 and EORTC 18951). Eur J Cancer 45: 1807-1814.

Atkins MB, Kunkel L, Sznol M, Rosenberg SA (2000) High-dose recombinant interleukin-2 therapy in patients with metastatic melanoma: long-term survival update. Cancer J Sci Am 6(Suppl 1): S11-S14.

Balch CM, Gershenwald JE, Soong S-J, Thompson JF, Atkins MB, Byrd DR, Buzaid AC, Cochran AJ, Coit DG, Ding S, Eggermont AM, Flaherty KT, Gimotty PA, Kirkwood JM, McMasters KM, Mihm MC, Morton DL, Ross MI, Sober AJ, Sondak VK (2009) Final version of 2009 AJCC melanoma staging and classification. J Clin Oncol 27: 6199-6206.

Chapman PB, Einhorn LH, Meyers ML, Saxman S, Destro AN, Panageas KS, Begg CB, Agarwala SS, Schuchter LM, Ernstoff MS, Houghton AN, Kirkwood JM (1999) Phase III multicenter randomized trial of the 
Dartmouth regimen versus dacarbazine in patients with metastatic melanoma. J Clin Oncol 17: 2745-2751.

Chapman PB, Hauschild A, Robert C, Haanen JB, Ascierto P, Larkin J, Dummer R, Garbe C, Testori A, Maio M, Hogg D, Lorigan P, Lebbe C, Jouary T, Schadendorf D, Ribas A, O'Day SJ, Sosman JA, Kirkwood JM, Eggermont AMM, Dreno B, Nolop K, Li J, Nelson B, Hou J, Lee RJ, Flaherty KT, McArthur GA (2011) Improved survival with vemurafenib in melanoma with BRAF V600E mutation. N Engl J Med 364: $2507-2516$

Delyon J, Mateus C, Lefeuvre D, Lanoy E, Zitvogel L, Chaput N, Roy S, Eggermont AMM, Routier E, Robert C (2013) Experience in daily practice with ipilimumab for the treatment of patients with metastatic melanoma: an early increase in lymphocyte and eosinophil counts is associated with improved survival. Ann Oncol 24: 1697-1703.

Diem S, Kasenda B, Martin-Liberal J, Lee A, Chauhan D, Gore M, Larkin J (2015) Prognostic score for patients with advanced melanoma treated with ipilimumab. Eur J Cancer 51(18): 2785-2791.

Eisenhauer EA, Therasse P, Bogaerts J, Schwartz LH, Sargent D, Ford R, Dancey J, Arbuck S, Gwyther S, Mooney M, Rubinstein L, Shankar L, Dodd L, Kaplan R, Lacombe D, Verweij J (2009) New response evaluation criteria in solid tumours: revised RECIST guideline (version 1.1). Eur J Cancer 45: 228-247.

Eton O, Legha SS, Moon TE, Buzaid AC, Papadopoulos NE, Plager C, Burgess AM, Bedikian AY, Ring S, Dong Q, Glassman AB, Balch CM, Benjamin RS (1998) Prognostic factors for survival of patients treated systemically for disseminated melanoma. J Clin Oncol 16: 1103-1111.

Flaherty KT, Robert C, Hersey P, Nathan P, Garbe C, Milhem M, Demidov LV, Hassel JC, Rutkowski P, Mohr P, Dummer R, Trefzer U, Larkin JMG, Utikal J, Dreno B, Nyakas M, Middleton MR, Becker JC, Casey M, Sherman LJ, Wu FS, Ouellet D, Martin A-M, Patel K, Schadendorf D (2012) Improved survival with MEK inhibition in BRAF-mutated melanoma. N Engl J Med 367: 107-114.

Hauschild A, Grob J-J, Demidov LV, Jouary T, Gutzmer R, Millward M, Rutkowski P, Blank CU, Miller WH, Kaempgen E, Martín-Algarra S, Karaszewska B, Mauch C, Chiarion-Sileni V, Martin A-M, Swann S, Haney P, Mirakhur B, Guckert ME, Goodman V, Chapman PB (2012) Dabrafenib in BRAF-mutated metastatic melanoma: a multicentre, open-label, phase 3 randomised controlled trial. Lancet 380: 358-365.

Hodi FS, O’Day SJ, McDermott DF, Weber RW, Sosman JA, Haanen JB, Gonzalez R, Robert C, Schadendorf D, Hassel JC, Akerley W, van den Eertwegh AJM, Lutzky J, Lorigan P, Vaubel JM, Linette GP, Hogg D, Ottensmeier CH, Lebbé C, Peschel C, Quirt I, Clark JI, Wolchok JD, Weber JS, Tian J, Yellin MJ, Nichol GM, Hoos A, Urba WJ (2010) Improved survival with ipilimumab in patients with metastatic melanoma. N Engl J Med 363: 711-723.

Kelderman S, Heemskerk B, van Tinteren H, van den Brom RRH, Hospers GAP, van den Eertwegh AJM, Kapiteijn EW, de Groot JWB, Soetekouw P, Jansen RL, Fiets E, Furness AJS, Renn A, Krzystanek M, Szallasi Z, Lorigan P, Gore ME, Schumacher TNM, Haanen JBAG, Larkin JMG, Blank CU (2014) Lactate dehydrogenase as a selection criterion for ipilimumab treatment in metastatic melanoma. Cancer Immunol Immunother 63: 449-458.

Larkin J, Ascierto PA, Dréno B, Atkinson V, Liszkay G, Maio M, Mandalà M, Demidov L, Stroyakovskiy D, Thomas L, de la Cruz-Merino L, Dutriaux C, Garbe C, Sovak MA, Chang I, Choong N, Hack SP, McArthur GA, Ribas A (2014) Combined vemurafenib and cobimetinib in BRAFmutated melanoma. N Engl J Med 371(20): 1867-1876.

Larkin J, Chiarion-Sileni V, Gonzalez R, Grob JJ, Cowey CL, Lao CD, Schadendorf D, Dummer R, Smylie M, Rutkowski P, Ferrucci PF, Hill A, Wagstaff J, Carlino MS, Haanen JB, Maio M, Marquez-Rodas I, McArthur GA, Ascierto PA, Long GV, Callahan MK, Postow MA, Grossmann K, Sznol M, Dreno B, Bastholt L, Yang A, Rollin LM, Horak C, Hodi FS, Wolchok JD (2015) Combined nivolumab and ipilimumab or monotherapy in untreated melanoma. N Engl J Med 373(1): 23-34.

Long GV, Stroyakovskiy D, Gogas H, Levchenko E, de Braud F, Larkin J, Garbe C, Jouary T, Hauschild A, Grob J-J, Chiarion-Sileni V, Lebbe C, Mandalà M, Millward M, Arance A, Bondarenko I, Haanen JBAG, Hansson J, Utikal J, Ferraresi V, Kovalenko N, Mohr P, Probachai V, Schadendorf D, Nathan P, Robert C, Ribas A, DeMarini DJ, Irani JG, Swann S, Legos JJ, Jin F, Mookerjee B, Flaherty K (2015) Dabrafenib and trametinib versus dabrafenib and placebo for Val600 BRAF-mutant melanoma: a multicentre, double-blind, phase 3 randomised controlled trial. Lancet 386(9992): 444-451.

Long GV, Stroyakovskiy D, Gogas H, Levchenko E, de Braud F, Larkin J, Garbe C, Jouary T, Hauschild A, Grob JJ, Sileni VC, Lebbe C, Mandalà M, Millward M, Arance A, Bondarenko I, Haanen JBAG, Hansson J, Utikal J, Ferraresi V, Kovalenko N, Mohr P, Probachai V, Schadendorf D, Nathan P, Robert C, Ribas A, DeMarini DJ, Irani JG, Casey M, Ouellet D, Martin A-M, Le N, Patel K, Flaherty K (2014) Combined BRAF and MEK inhibition versus BRAF inhibition alone in melanoma. $N$ Engl J Med 371(20): 1877-1888.

Manola J, Atkins M, Ibrahim J, Kirkwood J (2000) Prognostic factors in metastatic melanoma: a pooled analysis of Eastern Cooperative Oncology Group trials. J Clin Oncol 18: 3782-3793.

Postow MA, Chesney J, Pavlick AC, Robert C, Grossmann K, McDermott D, Linette GP, Meyer N, Giguere JK, Agarwala SS, Shaheen M, Ernstoff MS, Minor D, Salama AK, Taylor M, Ott PA, Rollin LM, Horak C, Gagnier P, Wolchok JD, Hodi FS (2015) Nivolumab and ipilimumab versus ipilimumab in untreated melanoma. N Engl J Med 372(21): 2006-2017.

Ribas A, Puzanov I, Dummer R, Schadendorf D, Hamid O, Robert C, Hodi FS, Schachter J, Pavlick AC, Lewis KD, Cranmer LD, Blank CU, O'Day SJ, Ascierto PA, Salama AKS, Margolin KA, Loquai C, Eigentler TK, Gangadhar TC, Carlino MS, Agarwala SS, Moschos SJ, Sosman JA, Goldinger SM, Shapira-Frommer R, Gonzalez R, Kirkwood JM, Wolchok JD, Eggermont A, Li XN, Zhou W, Zernhelt AM, Lis J, Ebbinghaus S, Kang SP, Daud A (2015) Pembrolizumab versus investigator-choice chemotherapy for ipilimumab-refractory melanoma (KEYNOTE-002): a randomised, controlled, phase 2 trial. Lancet Oncol 16(8): 908-918.

Robert C, Karaszewska B, Schachter J, Rutkowski P, Mackiewicz A, Stroiakovski D, Lichinitser M, Dummer R, Grange F, Mortier L, Chiarion-Sileni V, Drucis K, Krajsova I, Hauschild A, Lorigan P, Wolter P, Long GV, Flaherty K, Nathan P, Ribas A, Martin A-M, Sun P, Crist W, Legos J, Rubin SD, Little SM, Schadendorf D (2014a) Improved overall survival in melanoma with combined dabrafenib and trametinib. $N$ Engl $J$ Med 372(1): 30-39.

Robert C, Long GV, Brady B, Dutriaux C, Maio M, Mortier L, Hassel JC, Rutkowski P, McNeil C, Kalinka-Warzocha E, Savage KJ, Hernberg MM, Lebbé C, Charles J, Mihalcioiu C, Chiarion-Sileni V, Mauch C, Cognetti F, Arance A, Schmidt H, Schadendorf D, Gogas H, Lundgren-Eriksson L, Horak C, Sharkey B, Waxman IM, Atkinson V, Ascierto PA (2014b) Nivolumab in previously untreated melanoma without BRAF mutation. N Engl J Med 372(4): 320-330.

Robert C, Ribas A, Wolchok JD, Hodi FS, Hamid O, Kefford R, Weber JS, Joshua AM, Hwu W-J, Gangadhar TC, Patnaik A, Dronca R, Zarour H, Joseph RW, Boasberg P, Chmielowski B, Mateus C, Postow MA, Gergich K, Elassaiss-Schaap J, Li XN, Iannone R, Ebbinghaus SW, Kang SP, Daud A (2014c) Anti-programmed-death-receptor-1 treatment with pembrolizumab in ipilimumab-refractory advanced melanoma: a randomised dose-comparison cohort of a phase 1 trial. Lancet 384(9948): 1109-1117.

Robert C, Schachter J, Long GV, Arance A, Grob JJ, Mortier L, Daud A, Carlino MS, McNeil C, Lotem M, Larkin J, Lorigan P, Neyns B, Blank CU, Hamid O, Mateus C, Shapira-Frommer R, Kosh M, Zhou H, Ibrahim N, Ebbinghaus S, Ribas A (2015) Pembrolizumab versus ipilimumab in advanced melanoma. N Engl J Med 372(26): 2521-2532.

Robert C, Thomas L, Bondarenko I, O’Day S, Weber J, Garbe C, Lebbe C, Baurain JF, Testori A, Grob JJ, Davidson N, Richards J, Maio M, Hauschild A, Miller Jr WH, Gascon P, Lotem M, Harmankaya K, Ibrahim R, Francis S, Chen TT, Humphrey R, Hoos A, Wolchok JD (2011) Ipilimumab plus dacarbazine for previously untreated metastatic melanoma. N Engl J Med 364: 2517-2526.

Schadendorf D, Hodi FS, Robert C, Weber JS, Margolin K, Hamid O, Patt D, Chen T-T, Berman DM, Wolchok JD (2015) Pooled analysis of long-term survival data from phase II and phase III trials of ipilimumab in unresectable or metastatic melanoma. J Clin Oncol 33(17): 1889-1894.

Weber JS, D'Angelo SP, Minor D, Hodi FS, Gutzmer R, Neyns B, Hoeller C, Khushalani NI, Miller WH, Lao CD, Linette GP, Thomas L, Lorigan P, Grossmann KF, Hassel JC, Maio M, Sznol M, Ascierto PA, Mohr P, Chmielowski B, Bryce A, Svane IM, Grob J-J, Krackhardt AM, Horak C, Lambert A, Yang AS, Larkin J (2015) Nivolumab versus chemotherapy in patients with advanced melanoma who progressed after anti-CTLA-4 treatment (CheckMate 037): a randomised, controlled, open-label, phase 3 trial. Lancet Oncol 16(4): 375-384. 
Weide B, Elsässer M, Büttner P, Pflugfelder A, Leiter U, Eigentler TK, Bauer J, Witte M, Meier F, Garbe C (2012) Serum markers lactate dehydrogenase and S100B predict independently disease outcome in melanoma patients with distant metastasis. Br J Cancer 107: 422-428.

Wolchok JD, Kluger H, Callahan MK, Postow MA, Rizvi NA, Lesokhin AM, Segal NH, Ariyan CE, Gordon R-A, Reed K, Burke MM, Caldwell A, Kronenberg SA, Agunwamba BU, Zhang X, Lowy I,

Inzunza HD, Feely W, Horak CE, Hong Q, Korman AJ, Wigginton JM,
Gupta A, Sznol M (2013) Nivolumab plus ipilimumab in advanced melanoma. N Engl J Med 369: 122-133.

This work is published under the standard license to publish agreement. After 12 months the work will become freely available and the license terms will switch to a Creative Commons AttributionNonCommercial-Share Alike 4.0 Unported License. 